\title{
Assessment of risk factors of African Swine Fever in India: perspectives on future outbreaks and control strategies
}

\author{
Mousumi Bora ${ }^{1}$, Durlav Bora ${ }^{1}$, Manu $\mathrm{M}^{2}$, Nagendra Nath Barman ${ }^{1}$, Lakshya Dutta ${ }^{1}$, \\ Pesingi Pavan Kumar ${ }^{2}$, Suvaneeth $\mathrm{P}^{2}$, and Ramadevi Nimmanapalli ${ }^{2}$ \\ ${ }^{1}$ Assam Agricultural University College of Veterinary Science \\ ${ }^{2}$ Banaras Hindu University Institute of Agricultural Sciences
}

August 5, 2020

\begin{abstract}
Africa Swine Fever (ASF) is one of the most important transboundary diseases of pigs. ASF has been identified in India for the first time in domestic pigs from outbreaks reported in two of the North-Eastern states, Arunachal Pradesh and Assam in 2020. A total of 11 ASF outbreaks in different regions killed over 3700 pigs and devastated the economy of small-scale livestock owners of both the states. Considering the first outbreak of ASF in India, a generic risk assessment framework was determined to identify potential risk factors that might favour future emergence of the disease. Based on Indian scenario, we considered population density of host, farming practice, availability of biological vectors and wildlife reservoirs, epidemiological cycles and international trade to analyze the possibility of future outbreaks and chances of establishment of endemism. On critical analysis of the identified risk factors, we observed that the risk factors are well preserved in Indian geography and might participate in future outbreaks further disseminating the disease to nearby countries. Since no vaccine is currently available against ASF, the domestic and the wild-pigs (wild boars and the endangered pygmy hogs native to India) of this region are under constant threat of infection. For the near future this region will have to continue to rely on the implementation of preventive measures to avoid the devastating losses that outbreaks can cause. The various adaptive control strategies to minimize the risks associated with the transmission of ASF keeping our views to Indian settings have been described. The risk-analysis framework presented in the study will give a further understanding of the dynamics of disease transmission and will help to design control strategies and corresponding measures to minimize the catastrophic consequences of ASF disease.
\end{abstract}

\section{KEYWORDS}

African Swine Fever virus, outbreak, domestic pigs, wild-life reservoirs, risk assessment, control strategies

\section{INTRODUCTION}

African Swine Fever (ASF) is a highly fatal viral infectious disease that manifests as a haemorrhagic fever in affected pigs (Penrith and Vosloo, 2009). ASF has been listed as a priority disease in World Organisation for Animal Health (OIE) owing to its socio-economic importance and transboundary potential (OIE, 2020a). The first report of ASF was detected in Kenya as a disease entity distinct from Classical Swine Fever (CSF) (Montgomery, 1921). Since its first inception, ASF has spread from its historic range of Africa, to several countries in Europe (France, Italy, Malta, Belgium and the Netherlands and Iberian Peninsula) (Penrith and Vosloo, 2009; Blome et al., 2013) and more recently to Asia (China, Mongolia, Vietnam, Cambodia, Korea, Lao, Myanmar, Philippines and Indonesia) threatening both domestic and wildlife conservation (FAO, 2020a). The disease ASF is caused by African swine fever virus (ASFV) of genus Asfivirus and is currently the sole member of the family Asfarviridae (Alonso et al., 2018). ASFV infects domestic and wild swine (Sus scrofa), warthogs (Phacochoerus africanus; Phacochoerus aethiopicus) and bush pigs (Potamochoerus porcus ) (Alonso et al., 2018). ASFV can be transmitted directly during (i) contact between infected and 
susceptible pigs (ii) consumption of the meat from infected pigs (iii) bites of infected soft ticks (Ornithodoros species), and indirectly(iv) by contact with fomites contaminated by virus-containing matters such as blood, faeces, urine or saliva from infected pigs (Penrith and Vosloo, 2009). Clinical disease of ASF can manifest in multiple ways ranging from peracute (mortality $~ 100 \%$ ) to an asymptomatic infection (Penrith and Vosloo, 2009). Acute infections are typically characterized by a high fever, anorexia, lethargy, weakness, recumbency, diarrhoea and/or constipation, abdominal pain, hemorrhagic signs, respiratory distress, nasal and conjunctival discharge, and abortions in pregnant females followed by death within 6-13 days after the onset of clinical signs (Sanchez-Vizcaino, 2010). Subacute infections are often recorded with high mortality in young animals and include clinical signs such as abortion, fever, and transient haemorrhage with death or recovery within 3-4 weeks (Penrith and Vosloo, 2009; Schulz et al., 2017). Chronic infections are associated with low mortality and clinical signs such as intermittent or low fever, loss of appetite and depression which might develop over 2-15 months (Sanchez-Vizcaino, 2010).

India has reported the first outbreak of ASF in the domestic pig population of two of the North-Eastern states viz. Arunachal Pradesh and Assam to OIE on the $21^{\text {st }}$ May, 2020 (OIE, 2020b). The North Eastern Region (NE) of India, owing to its unique geographical location while sharing international boundaries with China, Bhutan, Bangladesh and Myanmar bears a constant threat of transboundary emerging diseases though its porous borders (Barman et al., 2016). Apart from the first outbreak of ASF in NE India, this region has also reported several other emerging diseases of pigs such as Porcine reproductive and respiratory syndrome (Rajkhowa et al., 2015) and PorcineCircovirus -2 infections (Mukherjee et al., 2018).In this article, the authors will discuss the risk factors/indicators that might favour the spread of ASF infections in India, its possibilities of establishment of endemic infections and the control strategies to prevent future outbreaks.

\section{FIRST EMERGENCE OF ASF IN INDIA}

An unusual mortality in pigs were reported earlier on January 2020 from Dhemaji, Biswanath, Lakhimpur, Sivasagar, Jorhat and Dibrugarh districts of Assam as well as from West Kameng, Papumpare, Lower Siang, Upper Siang, Lohit, Lepa Rada, East Siang, Namsai and Changlang districts of Arunachal Pradesh. After scrutiny of the clinical case reports, samples were tested for Classical Swine Fever (CSF, an endemic disease) at NERDDL and at College of Veterinary Sciences, Khanapara, Guwahati with support from ICARNational Research Centre on Pigs, Rani and ICAR Research Complex for NEH Region at Barapani. As the preliminary tests of the tissue samples of pigs from Assam conducted at College of Veterinary Sciences, Guwahati, indicated African Swine Fever (ASF), samples from both Assam and Arunachal Pradesh were sent to the OIE reference laboratory, ICAR-National Institute for High Security Animal Diseases (NIHSAD), Bhopal, where these samples were tested positive for ASF by both Real time PCR and nucleotide sequencing.

\section{VIRUS CLASSIFICATION}

African Swine Fever is caused by African Swine Fever virus (ASFV) belonging to family Asfarviridae and the only DNA arbovirus (arthropod borne) known so far (Alonso et al., 2018). ASFV is an enveloped virus with icosahedral morphology and an average diameter of $200 \mathrm{~nm}$ (Galindo and Alonso, 2017). ASFV genome consists of a linear double-stranded DNA molecule of 170-193 kbp depending on the isolate with terminal inverted repeats and hairpin loops (Dixon et al., 2013). To date, 24 distinct genotypes of ASFV have been described based on C-terminal (major structural protein) p72 gene sequencing (Bastos et al., 2003). The virus primarily infects cells of the mononuclear phagocytic system (monocytes and macrophages) and replicates in the cytoplasm (Chapman et al., 2008). Soft ticks of the genus Ornithodoros serve as biological vectors of ASFV (OIE, 2019a). All age groups from the members of the family Suidae are susceptible to ASFV infection (Mulumba-Mfumu et al., 2019).

\section{WARTHOGS, BUSH PIGS AND SOFT TICKS AS NATURAL RESERVOIRS}

African swine fever can lead to high mortalities in domestic pigs while being asymptomatic in the natural suid reservoir hosts (Jia et al., 2017). Wild pigs (warthogs and bush pigs), and soft ticks of the genus Ornithodoros serve as natural reservoirs in ASFV transmission (Costard et al., 2013). Wild pigs including warthogs and bush pigs may be persistently infected generally developing asymptomatic infections, often 
referred to as the sylvatic cycle (Kimberling and Teegarden, 1979). Young warthogs may develop a transient viremia to infect new ticks without developing clinical disease, and adult warthogs may be resistant to the pathogenic effects of the virus although the virus can be often extracted from their lymph nodes (Penrith, 2009).Soft ticks from the genus Ornithodoros are responsible for the transmission of ASFV in the environment and acts as a main source of infection (Burrage, 2013). Even though, soft ticks like Ornithodoros moubata and $O$. erraticus have been reported to be involved in the sylvatic transmission cycle of the virus in Africa and Europe respectively, several other species of Ornithodoros (O. moubata, O. sonrai, O. coriaceus , O. turicata , O. parkeri, and O. puertoricensis ) have also been confirmed as the biological vectors for transmission of ASF (Frant et al., 2017). Infection from the wild pigs to the domestic population is largely dependent on ticks of the Ornithodoros species than infections through contact between wild and domestic pigs (Costard et al., 2009). Apart from soft ticks, biting flies (Stomoxys spp.) have shown to be capable of transmitting the disease into the swine population (CSFPH, 2019).

\section{EPIDEMIOLOGICAL CYCLES OF ASF}

The epidemiology of ASF was described as comprising four independent epidemiologic cycles (i) sylvatic (ii) tick-pig (iii) domestic and (iv) wild boar-habitat cycle (a newly discovered cycle in Europe) (Chenais et al., 2018). The sylvatic cycle, mostly restricted to African continent, is maintained between Ornithodoros ticks and natural reservoirs (warthogs and bush pigs) that are resistant to the ASFV and usually do not develop any clinical disease (Plowright et al., 1994; Guberti et al., 2018). In the tick-pig cycle, the virus is transmitted among domestic pigs through ticks serving as a reservoir and allowing the virus to persist locally in the environment (Wilkinson, 1984). In the domestic cycle, the virus is transmitted among domestic pigs or from pig products to domestic pigs without the involvement of natural reservoirs (Chenais et al., 2019).The wild boar-habitat cycle is a newly described cycle in Central and Eastern Europe while investigating the epidemiological pattern of ASF infections in wild and domestic pig population (Chenais et al., 2018).This newly evolved epidemiological cycle involves wild boar (Sus scrofa), the wild boar habitat and their carcasses for the maintenance and transmission of ASFV to domestic pigs (Chenais et al., 2018). The wild boar-habitat cycle may describe the possibilities of new infections in areas with wild boar population and in the interspaces between wild and domesticated swine habitat such as a Wildlife Sanctuary or a National Park.

\section{RISK IDENTIFICATION AND ASSESSMENT OF ASF}

Considering the possibility of ASFV to cause future outbreaks and establishment of endemism in India, several factors that exert selection pressures on emergence of new animal diseases need to critically analysed. We identified some of the risk factors/indicators in Indian context which might serve as a connection for further emergence of ASF in this region. The identified risk factors of ASF are described critically keeping in view the social and ecological understanding of agriculture and food security of the human populations which depends on agriculture and livestock for their living.

\subsection{Population density of domestic pigs}

Among the livestock species, pigs find an important place in Indian economy as it not only contributes to the livelihood security of rural masses but also improves the socio-economic status of the marginal farmers and the weaker section of the society (NRC Pig, 2011). The North-Eastern (NE) region of India mostly comprises of a high proportion of tribal people where backyard pig farming is an integral part of their way of living (Talukdar et al., 2019). Apart from NE India, pig farming has been observed in several states of the mainland such as Jharkhand, West Bengal and Uttar Pradesh specially among the down trodden and tribal population as a backyard subsidiary enterprise (Kumar et al., 2004; Jeyakumar et al., 2014; Chauhan et al., 2016; Sahu et al., 2018). According to the latest livestock census report (2019), the current pig population is 9.06 million $(\mathrm{M})$, the highest being in the state of Assam (2.10 M) followed by Jharkhand (1.28 M), Meghalaya $(0.71 \mathrm{M})$, West Bengal $(0.54 \mathrm{M})$ and Chhattisgarh $(0.53 \mathrm{M})$ (Livestock Census, 2019).Over $70 \%$ of the pigs reared in India are of indigenous origin (dahd.nic.in). According to studies related to infectious diseases and group sizes, it has been found out that outbreaks of any disease reached higher prevalence when groups are larger and dense (Nunn et al., 2015). Majority of the marginal families involved in backyard farming usually 
keeps an average of 2-3 indigenous or crossbred pigs for fattening with zero to minimum inputs in terms of family labour and feeding (Kumar et al., 2007; Patra et al., 2016; Singh et al., 2019). Pig owners, specially from remote and rural settings are observed to show keen interest in small-scale pig farming (10-15 pigs per family) mostly with an aim to get avenues for additional income and savings for their children's education and medical treatment based on the locally available resources (Chauhan et al., 2016). Even though, pigs maintained in such locations are clustered into smaller groups, the rural households are connected close to each other, thus predisposing the animals to infectious animal diseases and their spread to closely reared/incontact animals. Therefore, considering the existing high density of domestic pig population in India, there is every chance that ASF might attain an endemic status if not controlled critically.

\subsection{Farming practice}

Pig farming in India is primarily an unorganized small-scale and backyard enterprise characterized by subsistence, low input-low output and technologically lagged activity dominated by small land holders (Chauhan et al., 2016; Talukdar et al., 2019). In majority of pig rearing areas in India, farmers follow a production system mostly under scavenging conditions, which depends on locally available unconventional feed like plants and limited amount of kitchen waste (Kumaresan et al., 2009; Shyam et al., 2017). Scavenging pigs can be found on both urban and rural areas of India where pigs are permitted to scavenge for feed during the day time around the household, streets and nearby forests, and then allowed to take rest in small enclosures at night. The present outbreaks of ASF reported from NE region of India were detected mostly from remote villages where scavenging system of rearing of pig is predominant and animals are allowed to move freely around the home in search of feed (free-grazing). Besides, swill feeding (garbage/food scraps) is a common practice throughout India, often concentrated around metropolitan centres as it is economical for pig rearing and production (Muthuramalingam et al., 2011; Ramesh et al., 2012). However, in most village settings, swills or feed wastes are not heat treated before feeding pigs and thus remains as a source of infection to healthy pig population. A study conducted by a group of researchers in the pig production system in mountainous regions of NE India have reported that pigs died of diseases are disposed either by burial or dumbed in nearby jungles (Kumaresan et al., 2009). The farmers in rural settings lack awareness on infectious diseases and their mode of transmissions. In general, veterinarians are not informed by livestock owners and most of the infectious disease of animals goes unreported.

The small-scale confined pig production is usually done by marginal farmers and group of household women for both subsistence and commercial reasons. Here, pigs are confined to pens made of local materials to more modern housing systems and fed with leaves, crop residues, agricultural by-products or prepared feed. The farmers owning such small-scale pig farms often search for traders within their marketing chain. The traders usually travel between villages and collect pigs to bring them to live animal markets or slaughter areas where mixing of animals at wet markets and during transport is more frequent (Shyam et al., 2016). Therefore, diseases confined to a group of pigs are more likely to spread to different regions due to purchase of infected piglets/pigs from unknown sources. Besides, it is not a common practice to quarantine the newly introduced animals in the farms. Moreover, in most rural and remote areas, there are no organized slaughterhouses or abattoirs and pigs are usually slaughtered in home or in open meat markets. Thus, sewage from these poorly equipped facilities is directly accessible to other animals as a source of food. Therefore, it is obvious that highly infectious diseases like ASF can easily spread at local level associated with free-range pig production, local pig movements and lack of basic biosecurity measures among the pig owners. Commercial pig-farms involved in high scale pig production in India are limited and can be found in urban and per-urban areas where agricultural and market opportunities are available (Mohakud et al., 2020). The risks of transmission of ASFV associated with the pig farming practice in Indian settings are described in Figure 1.

\subsection{Availability of tick vectors}

Soft ticks (Acari: Argasidae) are important vectors of disease-causing pathogens in human and animal populations including wild animals (de la Fuente et al., 2008). Previous studies have shown that the infected Ornithodoros ticks are able to retain the virus for long periods thus serving as a biological vector and transmit it to susceptible hosts (Plowright et al., 1994). In addition, members of Ornithodoros species can 
transmit ASFV from tick to tick through transstadial (Hess et al., 1989), sexual and transovarial transmission (Plowright et al., 1970) allowing the virus to persist even in the absence of viraemic hosts. Endemism of ASF in any country may depends upon the prevalence and geographical distribution of Ornithodoros species. In India, the prevalence of soft ticks has been found to be comparatively lower than hard ticks (Shyma et al., 2019). This might be because of limited studies on soft ticks especially on Ornithodoros species to even identify their geographical distribution. Ornithodoros ticks has been associated with transmission of ASF, Karshi virus or Langat virus associated encephalitis (tick-borne encephalitis virus complex) and Human relapsing fever (Manzano-Román et al., 2012). Among these diseases, louse borne human relapsing fever has been initially discovered in India in 1907 with the association of Pediculus humanus in the transmission of the causative agent Borrelia recurrentis (Mackie, 1907). Later a few case reports on tick borne human relapsing fever has been reported from Indian states of Kashmir (Kalra and Rao, 1951), Madhya Pradesh (Aher et al., 2008) and Karnataka (Veena et al., 2013) confirming the involvement of Ornithodoros ticks in their transmission. The present outbreak of ASF in India is still not known in the context of transmission involving tick vectors/biting flies/infective secretions and tissues or possibility of indirect transmission by fomites. Since, Ornithodoros species have already been found to be associated with other diseases and its prevalence has been reported from Gujarat (Sharma et al., 2017; Shyma et al., 2019), Nilgiri Hills and adjoining areas of Tamil Nadu (Kumar et al., 2014), there may be a possibility of involvement of Ornithodoros species with the present outbreak of ASF in the NE India. The paucity of research on prevalence of Ornithodoros ticks and their probable role in the transmission of various diseases of animal and public health importance in the country might further enhance the possibility of further outbreaks of ASF in other pig rearing states of India.

\subsection{Availability of wildlife reservoirs and their habitat}

AFSV is maintained in a stable equilibrium with its wildlife hosts, warthogs and soft ticks of Ornithodoros species, in a unique ecological niche (Netherton et al., 2019). Though the sylvatic cycle of ASFV in warthogs contrasts with the domestic cycle in swine, yet, in both instances, soft ticks of the genus Ornithodoros in warthog burrows and domestic pigpens serve as biological hosts and vectors (Calisher and Fenner, 2000). The wildlife reservoirs, warthogs are native to Africa and often found in abundance (de Jong et al., 2017). The Common warthog (Phacochoerus africanus ) is widely distributed over sub-Saharan Africa, and expanded its geographic range to West Africa eastwards to Eritrea and Ethiopia, southward through eastern Africa, and over much of southern Africa to southern Angola, Botswana, and Mozambique to northeast South Africa (de Jong et al., 2017). The Desert warthog (Phacochoerus aethiopicus ) is presently known only from south-eastern Ethiopia, western Somalia, and in central and eastern Kenya (d'Huart et al., 2011). Since warthogs are confined mostly to Africa, outbreaks of ASF recorded outside the continent (recent outbreaks in Europe and Asia including India) raises questions about the involvement of sylvatic cycles, but might have arises through other means of disease dissemination such as infected pig-derived products and circulation of Ornithodoros species across the borders. However, distribution of warthogs (desert warthogs in particular), is largely unstudied for which further field surveys are needed to better determine geographic limits, area of occupancy, abundance and the impacts of various human/livestock-raising activities on distribution and abundance (d'Huart et al., 2011). There are also limited investigations on bushpigs to understand their contribution in the epidemiology of ASF and the interactions between these natural hosts and domestic pigs (Ravaomanana et al., 2011).

\subsection{Correlation between the epidemiological cycles of ASF}

The ASF outbreaks in several countries in Europe in the year 2014-2017, seems to follow the common domestic epidemiological cycle, i.e. the infection circulates among small pig farms, affecting few commercial farms, and frequently spills over to wild boars (EFSA, 2014).From these data, a previously undescribed epidemiologic cycle of ASF became evident: a cycle that focuses on the wild boar population and its habitat as a virus reservoir and led to the addition of a new cycle known as 'wild boar-habitat cycle' (Chenais et al., 2018; FAO, 2020b). This cycle is characterized by (i) direct transmission between infected pigs/wild-boar and susceptible wild boar; and (ii) indirect transmission through ASF contaminated carcasses in the habitat 
and the possible subsequent intraspecies scavenging, and thus, the cycle continues (Probst et al., 2017).

Possibility of future outbreaks or establishment of endemism of ASF in India will depend upon the maintenance of epidemiological cycles of ASF as well as distribution of reservoirs and susceptible hosts. We have analysed the four established epidemiological cycles of ASF from Indian perspective to describe the risk associated with each cycle (Figure 2).

\subsubsection{Sylvatic cycle}

Sylvatic cycle is maintained between the natural reservoirs and biological vectors of ASFV without causing disease in the reservoir hosts. This cycle is not likely to occur in Indian scenario because of absence of spatial distribution of the natural reservoirs i.e. warthogs and bush pigs. Even though studies have shown the prevalence of Ornithodoros ticks in India, absence of reservoir hosts from the epidemiological triad will avert perpetuation of ASFV in the environment, thus, supressing the importance of the sylvatic cycle.

\subsubsection{Tick-pig cycle}

The maintenance of the tick-pig cycle can be related to the sylvatic cycle in regions where natural reservoirs of the virus are present and ticks serve as a transmitting medium to the domestic population from the wild reservoir habitat (Chenais et al., 2019). This cycle can still be maintained by transboundary migration of ticks harbouring the virus and allowing it to persist locally in the environment. The distribution of soft ticks across the world is not limited to a certain bio-geographic region and has been found in new ecological environment by the dissemination of immature phases by migratory birds and other climatic factors (Manzano-Roman et al., 2012). Dissemination of soft ticks from the neighbouring countries with similar climatic, socio-economic and demographic characteristics will always pose a threat for future emergence of ASF in India. Therefore, investigations related to soft tick distribution modelling in country is extremely crucial to prevent disease outbreaks.

\subsubsection{Domestic cycle}

In this cycle ASFV is transmitted from contaminated pig products to domestic pigs by the involvement of human activities such as trade and slaughter (Chenais et al., 2019). The outbreak of ASF in India can be related to the domestic cycle, where domestic pigs might have attained the infection by means of potential environmental contamination with ASFV through virus escape from infected populations of a nearby country. Maintenance of the domestic cycle endemism in the infected zones and incursion into a different location within the Indian geographic setting is possible because, in most rural settings, pig owners are not aware of the basic biosecurity measures in the farm level. Pigs while on the incubation period of an infectious disease are often taken to live animal markets unintentionally or being unaware of disease symptoms. Moreover, slaughter house waste management system is very poor in India (dahd.nic.in). Unavailability of organized slaughter houses in rural and per-urban premises makes effective management of waste difficult. The contaminated waste generated from such slaughter houses or pig markets will remain as a source of infection to susceptible animals in nearby regions.

\subsubsection{Wild boar-habitat cycle}

Wild boar is one of the most widespread group of mammals, which can be found on every continent expect Antarctica (He, 2014). The Indian crested wild-boar (Sus scrofa cristatus ) is seen in most of the wildlifeprotection sanctuaries and is widely distributed in India, Sri Lanka, Nepal, Thailand and Myanmar (Naish, 2015).Wild boars exhibit a home range behaviour, in which the movements of these animals are generally restricted to a defined area over an extended period of time. However, depending upon ecological conditions, these animals may roam about widely in search of better forage conditions (Allwin et al., 2016). Presently, the wild boar population in India are fragmented and can be observed in isolated groups. Some of these isolated populations can become locally overabundant and depend upon agricultural crops especially in and around the protected areas and village interface areas for a major part of their food requirement (Chauhan et al., 2009). While utilizing the agro-ecosystem for food, resource and shelter, contaminated food waste originating from the infected domestic pigs can initiate an ASF epidemic which may accidentally be released 
into a wild boar habitat. Infections disseminated to a group of wild-boar will persist in the wild-boar habitat and their carcasses. This cycle will continue to infect healthy wild-boar and domestic habitat. Besides, as discussed earlier, in most of the Indian pig rearing states, carcasses or contaminated materials of infected domestic pigs are usually disposed in jungles or thrown in rivers. By doing so, it can not only be a source of infection to natural host and wildlife reservoirs, but also to pygmy hogs population (Porcula salvania), an endangered species native to India and the only known population that lives in Assam which is estimated to be less than 250 in numbers (Meijaard et al., 2019). The susceptibility of pygmy hogs to ASFV is unclear , although Classical Swine Fever virus, an RNA virus that causes a disease with similar clinical signs to ASFV, can infect and kill pygmy hogs (Barman et al., 2012).

Based on the epidemiological cycles, the tick-pig, the domestic and the wild boar-habitat cycles are important in emergence of future outbreak of ASF and should be critically investigated to identify the transmission patterns and to implement control strategies.

\subsection{International trade}

At the global level, international trade, despite bringing potential health benefits through economic growth is one of the major driving factors of emerging diseases of animals as well as humans (Labonte et al., 2011). At present, ASF is a global threat to food security and economic stability of nations (Evans, 2019). Already, China, a home to half the world's pig population has lost a third of its pigs (about $100 \mathrm{M}$ ) to the devastating outbreak of ASF in the year 2018 and estimated to have led to a direct economic loss of one trillion yuan (approximately142 billion USD)(Huang, 2020).Besides China, the country Vietnam, where the pork industry is worth approximately 4 billion USD, has confirmed several outbreaks of ASF in the recent years (Evans, 2019).In India pork production is limited, representing only $9 \%$ of the country's animal protein sources. Production of pork is concentrated only in few India states and mainly in the NE region of the country primarily consisting of backyard and informal sector producers (dahd.nic.in). As per Government of India reports, the total pork production in the year 2014-15 was 464.11 thousand tons. The Indian market for processed pork products is small, and the majority of this market is supplied through imports by Belgium, Sri Lanka, Spain, Italy and the Netherlands in recent years (dahd.nic.in; USDA FAS 2016).India's global interaction in import of pork and pork products and human movements in dealing pigs might spread infectious diseases like ASF to emerge further outbreaks.

The listed risk factors or indicators and the critical risk control measures to reduce or eliminate threat of future emergence of ASF in India are described in Figure. 3. However, reviewing and updating the identified risks is an important future research for the global control and eradication of ASF.

\section{RESEARCH GAPS}

The most significant knowledge gaps in the prevention and control of ASF are (i) correlation of wild boar and ASF occurrence (ii) ASFV survival and transmission (iii) Biosecurity and (iv) Surveillance (Alvarez et al., 2019).To control ASF in countries where the wild-boar habitat cycle persists, estimation of wild-boar population in an area, correlation between wild-boar and ASF occurrence, mechanism of ASFV spread and persistence in the wild-boar population and host to host transmission is required to be critically analysed. With relation to ASFV survival and transmission, the role of vectors (Soft ticks/biting flies) needs to be further investigated (particularly in Indian scenario). Biosecurity measure is another significant gap in developing countries where pig production is a major source of economy. Livestock owners and farmers in villages and remote areas are not aware of biosecurity measures and being unable to identify the most effective measure for preventing infectious animal diseases bears severe economic loss. In such situations, veterinarians and para-veterinarians need to play a leading role to strengthen the veterinary services by educating the livestock owners about the disease and its prevention as well as should carry on consistent awareness programmes on infectious disease management. Surveillance is another research gap with respect to ASF prevention and control and is considered as a high priority. To avoid or to limit future outbreaks a strategic plan for control of ASF will be required for which we presume integrated (active and passive) surveillance is required as soon as possible. The major research gaps in ASF prevention are appropriately 
described by a study carried out by Alvarez and co-workers (Alvarez et al., 2019). Apart from the mentioned research gaps identified for ASF, unavailability of a vaccine till date makes the diseases difficult to control and once the disease is introduced into a pig population, culling of animals remain the only effective disease control option.

\section{PREVENTION AND CONTROL STRATEGIES}

African Swine Fever is devastating to the swine industry and currently, there is no commercially available vaccine to control the disease (Gaudreault and Richt, 2019). The development of vaccines against ASFV has been almost entirely neglected, mainly due to the technical difficulties involved in its development, gaps in knowledge concerning ASFV virulence factors (Rock, 2017) and to the fact that ASF was considered an 'exotic' disease in developed countries. However, the situation has dramatically changed with the recent emergence of the virus to Europe and Asia, threatening the global swine industry. Efforts to develop ASF vaccines are ongoing with different vaccine strategies. Among them, gene-deleted vaccines have shown promising results in eliciting effective immune responses (Chen et al., 2020; Borca et al., 2020; Reis et al., 2017; O'Donnell et al., 2017; Monteagudo et al., 2017; O'Donnell et al., 2015a; O'Donnell et al., 2015b). In absence of effective vaccines, the need of implementing alternate measures of prevention is important and critical to control the disease:

\subsection{Zoning}

Zoning is one of the early actions to be taken when there is an incursion of ASF into a country. Zoning is the proclamation of geographical areas within a country into infected zones, surveillance zones and free zones. To prevent further spread of infection, the infected zones should implement two objectives: (i) quarantine and livestock movement controls and (ii) remove sources of infection as quickly as possible through slaughter of potentially infected pigs, safe disposal of carcasses and decontamination. Accordingly, active disease surveillance and preventing the entry of the disease by banning entry of pigs and pig products from the infected zones are actions which are associated with ASF surveillance and disease-free zones respectively (FAO, 1999).

\subsection{Quarantine facilities}

Quarantine procedures to contain the disease, including pig-movement controls and prohibitions on the sale of potentially infected pig products should be followed appropriately according to Government of India initiated Animal Quarantine and Certification services. The quarantined period depends on the incubation period of a disease and usually a quarantine period of 3 weeks is set for observation of pig diseases (dahd.nic.in).

\subsection{Biosecurity in scavenging pig production systems}

The implementation of biosecurity measures in scavenging pig production systems is usually constrained by the producers' limited capacity to invest resources and time, and by the nature of scavenging pig production (FAO, 2010). In scavenging systems, measures related to introduction of new piglets from unknown sources, monitoring the health status and unusual deaths of scavenger pigs, particularly regarding diseases of concern, should be given prime attention. Sometimes, a farmer may prefer to sell disease suspected animals to slaughter houses rather than undertaking control measures. The marketing of sick animals under scavenging rearing is a serious disease risk as these incubating or excreting sick animals disseminate disease very quickly to the healthy herd. Besides, practice of feeding untreated pig swill must be strictly avoided which has been practised for centuries in most of the developing and poor countries. Any unusual death of pigs should be immediately reported to veterinarians to know the biosecurity measures, proper disposal of animals and disinfection of farm and premises. Even if disinfection is unlikely to be practicable, cleaning of night shelters/enclosures and equipment must be emphasized (FAO, 2010). However, considering the biosecurity and socio-economic importance of pig farming in India, the practice of scavenging rearing should be prohibited to prevent contact with other domestic pigs, wildlife, rodents, birds and other livestock which creates favourable conditions for infectious disease spread.

\subsection{Biosecurity at backyard and small-scale farms}


Biosecurity of pigs at backyard and small-scale farms should be effectively maintained to avoid the exposure of new or previously unknown pathogens in a farm, reduce the effect of endemic diseases in an area and limit the circulation of infectious diseases to nearby farms. Segregation, cleaning and disinfection are the major elements of biosecurity at farm level. Implementation of quarantine measures of newly introduced animals, controlling the entry of pigs from outside farms/markets/villages, proper fencing of the farm area to prevent people, animals and birds which may serve as mechanical vectors of ASF transmission and maintaining adequate distances between farms are the important components of segregation (FAO, 2010). Households with small scale pig farms are encouraged for routine cleaning of pens and premises which includes quick removal of food, faeces, litter and dust followed by disinfection using approved disinfectants.

\subsection{Interstate movement}

Considering the first outbreak of ASF in Assam and Arunachal Pradesh states of India, prohibition of interstate movement of domestic pigs from the affected regions to a different part of the country should be given the highest priority as such movement may spread the infection to new geographical locations Subacute and chronic forms of ASF might take 3-4 weeks of time to complete the incubation period. In such situations, pig vendors might take advantage of a long incubation period and could introduce infected stock quite successfully to buyers from a different state to disease-free zones. Therefore, development of systems to monitor the health status and to improve the traceability of relocated pigs (domestic and wild pigs) in order to enhance animal infectious disease surveillance, reporting, and response is advisable.

\subsection{Illegal import of contaminated pork and pork products}

There is a greater chance of introduction of disease like ASF when contaminated pork and pork products are illegally imported from other countries for personal consumption or commercial purpose. Pathogens like ASFV are particularly challenging due to their prolonged infectiousness in pork products (Adkin et al., 2004). The porous international borders particularly in the NE region of India and migration of live pigs or illegal imports from the neighbouring countries like Myanmar, Nepal, Bhutan or China will make the country vulnerable for transboundary diseases (dahd.nic.in). Therefore, strict monitoring protocols should be sufficiently timed to detect transboundary movement of live animals or products to minimize the associated risk of hazards/pathogens.

\subsection{Surveillance}

Early disease detection is the key to maintain a sound animal health and is the most effective way to control ASF (Gervasi et al., 2020). Laboratory diagnosis for detection of ASF as well differentiation of ASF with diseases with similar symptoms such as CSF, Acute salmonellosis, Swine erysipelas, Porcine dermatitis and nephropathy syndrome, and Aujeszky's disease should be implemented with proven and rapid diagnostic techniques to establish an accurate diagnosis within a short time. Polymerase Chain Reaction (PCR) is currently the most commonly used technique for the etiological diagnosis of ASF by amplifying the fragment of viral DNA present in the sample (Sanchez-Vizcaino, 2010).However, in developing countries like India, laboratories to detect such infectious diseases are often sparely distributed and access may be limited by economic or geographical factors. In such situations, the use of user-friendly kits or pen-side diagnostics (lateral flow assay, biosensors, mobile PCR assay and isothermal assay techniques) (Goswami and Borkataki, 2017) can have great potential to detect the disease in laboratory protocols. For the rapid detection of antigen in the field, the use of economic and simple tools such as immunochromatographic strips are suitable alternate diagnostic device essential for surveillance and control strategies (Cappai et al., 2018).It is also important to note that, veterinarians and livestock producers should be informed of the risk of ASF and the importance of reporting an outbreak by means of training and awareness camps by disease experts and professionals to ensure good field surveillance. Early disease detection, will, therefore, depend on the right balance between field surveillance and laboratory measures of disease detection.

\subsection{Culling of pigs}

Pigs infected with ASF must be culled/slaughtered immediately using humane methods which should result 
in immediate death or immediate loss of consciousness lasting until death. For biosecurity considerations, infected animals should be killed first, followed by in-contact animals, and then the remaining animals. Different methods of humane killing have been adopted based on different age groups of animals. The neonatal pigs can be killed with free bullet, non-penetrative captive bolt, electrical applications, $\mathrm{CO}_{2} /$ air mixture, nitrogen or inert gas mixed with $\mathrm{CO}_{2}$ and injection with barbiturates. Whereas, the adult pigs can be killed using free bullets, electrical applications and injection with barbiturates (OIE, 2019b). The operational procedures of killing should be adopted keeping in view the biosecurity and environmental aspects.

\subsection{Disposal of carcasses}

Disposal of carcasses should be carried out in such a way that the carcasses should no longer constitute a risk for further spread of the pathogen to the susceptible animals by direct or indirect means. In case of ASF, method of safe disposal includes(i) rendering, (ii) incineration (iii) burning or (iv) deep burial on the spot (OIE, 2019b). Incineration or rendering is the most effective and easy way to dispose of carcasses. However, the movement of infected carcasses to the rendering plant may again pose a certain risk of spreading the disease and might not be feasible in Indian situations. Burning of carcasses in an outdoor area can also be done in several ways: pyre burning, pit burning, above-ground incineration or a combination of the above methods. However, deep burial is a better option which can be done through trench burial or mass burial and in both the cases, the carcasses should be disinfected. Burial pits should be deep enough to ensure a soil layer of at least 1 metre above the carcass to prevent scavenging and to avoid contamination (Guberti et al., 2018).

\subsection{Disinfection of infected premises}

African swine fever virus is extremely stable in the environment and is efficiently transmitted via contaminated blood and meat of infected animals. It can persist in excretions for approximately 3 days at $37 \mathrm{degC}$ (3.71 and 2.88 days in faeces and urine respectively) (Davies et al., 2017), 11-22 days in viraemic blood at 37 (Plowright and Parker, 1967), over 84 to 155 days in raw meat stored under 4-8 (EFSA, 2014), several months in boned meat and years in frozen carcasses at 4-8 (Mebus, 1997).

Therefore, decontamination of animal houses, sheds, pens, yards, water-troughs and nearby areas is extremely important to reduce the risk of contaminating the environment with the ASFV. Appropriate disinfectants that are effective in inactivation of ASFV include $2 \%$ sodium hydroxide, detergents and phenol substitutes, sodium or calcium hypochlorite (2-3\% chlorine) and iodine compounds (FAO, 1999; DADF, 2020).

\subsection{Investigations on prevalence of soft ticks}

Distribution of argasid or soft ticks can be found throughout the world except for places with extreme climatic conditions (Estrada-Pena et al., 2012; Manzano-Roman et al., 2012). However, the distribution of specific species of soft tick is more limited or may be very extensive, depending on factors such as the adaptability of each particular species to new ecological environments, the dissemination of immature phases by migratory birds and the ability of adult specimens to infest different host species (Manzano-Roman et al., 2012). Considering the involvement of Ornithodoros ticks as a biological vector of ASF it is also possible that species that have never been identified in India may be imported from other continents contributing to a geographic distribution of particular species in constant to evolution. Therefore, an extensive investigation on the prevalence of Ornithodoros species is important to know the status of their distribution throughout the country and should be included in control strategies.

Along with the critical preventive and control measures mentioned for ASF, public-awareness and education campaigns are important integral elements of the disease control strategies. Disease awareness campaigns should be targeted in pig rearing areas in India because rural farmers lack knowledge on animal diseases, clinical symptoms and biosecurity measures. Exotic diseases like ASF should be given equal importance as human diseases when it comes to the socio-economic status of developing nations like India since a majority of the population depends on agriculture and livestock farming for food security and livelihood. 


\section{CONCLUSION}

African Swine Fever in India has probably emerged through a neighbouring country, that shares its border with India. Genetic characterization and molecular evolutionary analysis to trace the ancestors of the present outbreak are ongoing. As per the recent statement from OIE, outbreaks of ASF in India lead to a current count of over 3700 dead pigs in affected regions (OIE, 2020b). The current statistics and data on the number of pigs died due to the disease are still undergoing revisions and will be updated soon by Animal Husbandry departments of Arunachal Pradesh and Assam states of India. In the present study, we identified the underlying risk factors that might favour future outbreaks of ASF in the Indian pig population. On qualitative risk assessment analysis, we observed that the identified risk factors are well preserved in Indian geography and might participate in future outbreaks in the country or disseminating the disease to nearby countries. Therefore, the described risk factors should be critically considered and each risk factor should be reassessed at a regional level. Immediate containment measures should be implemented to control the disease, followed by establishing a strategic research plan on surveillance and sero-epidemiology of ASF on domestic and wild pig-population. Studies on the involvement of biological vectors in the perpetuation and transmission of ASFV is also important to estimate these risks more accurately in Indian scenario.

\section{ACKNOWLEDGEMENTS}

The authors are thankful to the Dean and Director of Research of College of Veterinary Sciences, Assam Agricultural University, Guwahati and Director, Institute of Agricultural Sciences (IAS), Banaras Hindu University (BHU), Uttar Pradesh to approve the research.

\section{CONFLICT OF INTEREST}

The authors certify that they have no affiliations with or involvement in any organization or entity with any financial interest, non-financial interest in the subject matter or materials discussed in this

manuscript.

\section{AUTHOR CONTRIBUTIONS}

MB, DPB and NNB outlined the present model of the review. MB, MM and PPK prepared the framework, complied and analysed the risk factors. MB and NNB wrote the manuscript. LJD, SP and RN reviewed and edited its final version. All the authors read and approved the final manuscript.

\section{ETHICAL STATEMENT}

The authors confirm that the ethical policies of the journal, as noted on the journal's author guidelines page, have been adhered to. No ethical approval was required as the current review was conducted based on open data in research platforms.

\section{DATA AVAILABILITY}

Data sharing is not applicable to this article as no new data were created or analysed in this study.

\section{ORCID}

Mousumi Bora https://orcid.org/0000-0002-7609-2437

Durlav Prasad Bora https://orcid.org/0000-0002-5629-7929

M Manu https://orcid.org/0000-0002-3146-4436

Lakshya Jyoti Dutta https://orcid.org/0000-0002-8528-5679

Pesingi Pavan Kumar https://orcid.org/0000-0002-9226-1181

Suvaneeth Poovathikkal https://orcid.org/0000-0002-5429-8506

\section{REFERENCES}


Adkin, A., Coburn, H., England, T., Hall, S., Hartnett, E., Marooney, C., Wooldridge, M., Watson, E.,

Cooper, J., Cox, T., \& Seaman, M. (2004). Risk assessment for the illegal import of contaminated meat and meat products into Great Britain and the subsequent exposure of GB livestock (IIRA): foot and mouth disease (FMD), classical swine fever (CSF), African swine fever (ASF), swine vesicular disease (SVD). New Haw: Veterinary Laboratories Agency.

Aher Atul, R., Shah, H., Rastogi, V., Tukaram, P. K., \& Choudhury, R. C. (2008). A case report of relapsing fever. 2008. Indian Journal of Pathology 83 Microbiology . 51(2) : 292-293

Allwin B, Swaminathan R, Mohanraj A, Suhas GN, Vedaminckam S, Gopal, S and Kumar, M. 2016. The Wild Pig (Sus scrofa) Behavior -A Retrospective Study. The Journal of Veterinary Science \& Technology. 7: 333 .

Alonso, C., Borca, M., Dixon, L., Revilla, Y., Rodriguez, F., \& Escribano, J. M. (2018). ICTV virus taxonomy profile: Asfarviridae. Journal of General Virology, 99 (5), 613-614.

Alvarez, J., Bicout, D., Boklund, A., Botner, A., Depner, K., .. \& Viltrop, A. (2019). Research gap analysis on African swine fever. European Food Safety Authority Journal , 17 (8), e05811.

Barman, N. N., Bora, D. P., Khatoon, E., Mandal, S., Rakshit, A., Rajbongshi, G., .. \& Kumar, S. (2016). Classical swine fever in wild hog: report of its prevalence in northeast India. Transboundary and Emerging Diseases, 63(5), 540-547.

Barman, N. N., Bora, D. P., Tiwari, A. K., Kataria, R. S., Desai, G. S., \& Deka, P. J. (2012). Classical swine fever in the pygmy hog. Rev. Sci. Tech, 31 , 919-930.

Bastos, A. D., Penrith, M. L., Cruciere, C., Edrich, J. L., Hutchings, G., Roger, F., .. \& Thomson, G.

R. (2003). Genotyping field strains of African swine fever virus by partial p72 gene

characterisation. Archives of virology , 148 (4), 693-706.

Blome, S., Gabriel, C., \& Beer, M. (2013). Pathogenesis of African swine fever in domestic pigs and

European wild boar. Virus research, 173 (1), 122-130.

Borca, M. V., Ramirez-Medina, E., Silva, E., Vuono, E., Rai, A., Pruitt, S., .. \& Gladue, D. P. (2020). Development of a highly effective African swine fever virus vaccine by deletion of the I177L gene results in sterile immunity against the current epidemic Eurasia strain. Journal of Virology, 94 (7).

Burrage, T. G. (2013). African swine fever virus infection in Ornithodoros ticks. Virus

research, 173 (1), 131-139.

Calisher, C., \& Fenner, F. (2000). Macroecology and Microecology of Viruses of Terrestrial Mammals.

In Viral Ecology. Academic Press.

Cappai, S., Sanna, G., Loi, F., Coccollone, A., Marrocu, E., Oggiano, A., .. \& Bandino, E. (2018).

African swine fever detection on field with antigen rapid kit test. J Anim Sci Res , 2 (3).

Chapman, D. A., Tcherepanov, V., Upton, C., \& Dixon, L. K. (2008). Comparison of the genome sequences of non-pathogenic and pathogenic African swine fever virus isolates. Journal of General Virology , 89 (2), 397-408.

Chauhan, A., Patel, B. H. M., Maurya, R., Kumar, S., Shukla, S., \& Kumar, S. (2016). Pig production system as a source of livelihood in Indian scenario: An overview. Int J Sci Environ Technol, 5(4), 2089-96. 
Chauhan, N. P. S., Barwal, K. S., \& Kumar, D. (2009). Human-wild pig conflict in selected states in India and mitigation strategies. Acta Silvatica et Lignaria Hungarica: An International Journal in forest, wood and Environmental sciences, 5, 189-197.

Chen, W., Zhao, D., He, X., Liu, R., Wang, Z., Zhang, X., .. \& Wang, L. (2020). A seven-gene-deleted African swine fever virus is safe and effective as a live attenuated vaccine in pigs. Science China Life Sciences, $1-12$.

Chenais, E., Depner, K., Guberti, V., Dietze, K., Viltrop, A., \& Stahl, K. (2019). Epidemiological considerations on African swine fever in Europe 2014-2018. Porcine health management, 5(1), 1-10.

Chenais, E., Stahl, K., Guberti, V., \& Depner, K. (2018). Identification of wild boar-habitat epidemiologic cycle in African swine fever epizootic. Emerging Infectious Diseases, 24(4), 810.

Costard, S., Mur, L., Lubroth, J., Sanchez-Vizcaino, J. M., \& Pfeiffer, D. U. (2013). Epidemiology of African swine fever virus. Virus research, 173 (1), 191-197.

Costard, S., Wieland, B., De Glanville, W., Jori, F., Rowlands, R., Vosloo, W., .. \& \& Dixon, L. K. (2009). African swine fever: how can global spread be prevented?. Philosophical Transactions of the Royal Society B: Biological Sciences, 364(1530), 2683-2696.

CSFPH. (2019). African Swine Fever. The Centre for Food Security and Public Health. Retrieved from http://www.cfsph.iastate.edu/Factsheets/pdfs/african_swine_fever.pdf

DADF. (2020). National Action Plan for control, containment and eradication of African Swine

Fever. Ministry of Fisheries, Animal Husbandry and Dairying Department of Animal Husbandry and Dairying Government of India. Retrieved from http://dadf.gov.in/sites/default/filess/ASF_NAP_Booklet.pdf dadh.nic.in. Department of Animal Husbandry, Dairying. Government of India. Ministry of Fisheries, Animal Husbandry and Dairying. Retrieved from http://dahd.nic.in/sites/default/filess/NAP\%20on\%20Pig\%20.pd Davies, K., Goatley, L. C., Guinat, C., Netherton, C. L., Gubbins, S., Dixon, L. K., \& Reis, A. L. (2017). Survival of African swine fever virus in excretions from pigs experimentally infected with the Georgia 2007/1 isolate. Transboundary and emerging diseases , 64 (2), 425-431.

de Jong, Y. A., Cumming, D., d'Huart, J., \& Butynski, T. (2017). Phacochoerus africanus (errata version published in 2017) The IUCN Red List of Threatened Species 2016: e. T41768A1 09669842.

de la Fuente, J., Estrada-Pena, A., Venzal, J. M., Kocan, K. M., \& Sonenshine, D. E. (2008). Overview: ticks as vectors of pathogens that cause disease in humans and animals. Front Biosci, 13 (13), 6938-6946.

d'Huart, J., de Jong, Y. A., \& Butynski, T. (2016). Phacochoerus aethiopicus. The IUCN Red List of Threatened Species 2016: e. T41767A44140316.

Dixon, L. K., Chapman, D. A., Netherton, C. L., \& Upton, C. (2013). African swine fever virus replication and genomics. Virus research, 173(1), 3-14.

EFSA. (2014). Scientific Opinion on African swine fever. EFSA Journal 2014; 12 (4): 3628, 77 pp. Estrada-Pena, A., Ayllon, N., \& De La Fuente, J. (2012). Impact of climate trends on tick-borne pathogen transmission. Frontiers in physiology , 3, 64 . 
Evans, I. (2019). African swine fever poses a serious threat to global food security experts say. Elsevier Connect. Retrieved from https://www.elsevier.com/connect/african-swine-fever-poses-a-serious-threat-toglobal-food-security-experts-say.

FAO. (2010). Food and Agriculture Organization of the United Nations/World Organisation for Animal Health/World Bank. Good practices for biosecurity in the pig sector - Issues and options in developing and transition countries. FAO Animal Production and Health Paper No. 169. Rome, FAO.

FAO. (1999). Food and Agricultural Organization. Manual on livestock disease surveillance and information systems. Animal health manual No. 8. Retrieved from http://www.fao.org/3/Y0510E/Y0510E06.htm.

FAO. (2020a). ASF situation in Asia update. Retrieved from. http://www.fao.org/ag/againfo/programmes/en/empres/ASF/situation_update.html

\section{FAO. (2020b). ASF Virology. Retrieved from.}

\section{http://www.fao.org/ag/againfo/programmes/en/empres/ASF/Virology.html}

Frant, M., Woźniakowski, G., \& Pejsak, Z. (2017). African swine fever (ASF) and ticks. No risk of tickmediated ASF spread in Poland and Baltic states. Journal of veterinary research , 61 (4), 375-380.

Galindo, I., \& Alonso, C. (2017). African swine fever virus: a review. Viruses , 9 (5), 103.

Gaudreault, N. N., \& Richt, J. A. (2019). Subunit vaccine approaches for African swine fever virus. Vaccines $, 7(2), 56$.

Gervasi, V., Marcon, A., Bellini, S., \& Guberti, V. (2020). Evaluation of the Efficiency of Active and Passive Surveillance in the Detection of African Swine Fever in Wild Boar. Veterinary Sciences, $7(1), 5$.

Goswami, P., \& Borkataki, S. (2017). Pen Side Diagnosis of Infectious disease-A Current Status. International Journal of Advanced Research and Review, 2 (6), 44-55.

Guberti, V., Khomenko, S., Masiulis, M., \& Kerba, S. (2018). Handbook on African Swine Fever in wild boar and biosecurity during hunting. Handbook on African Swine Fever in wild boar and biosecurity during hunting.

He, H. (2014). Feral swine diseases prevention and control in China. International Workshop on Feral Swine Disease and Risk Management. Retrieved from http://www.cvmbs.colostate.edu/aphi/feralswine/PDFs/HongxuanHe\% Hess, W. R., Endris, R. G., Lousa, A., \& Caiado, J. M. (1989). Clearance of African swine fever virus from infected tick (Acari) colonies. Journal of medical entomology , 26 (4), 314-317.

Huang, Y. (2020). The Biggest Animal Disease Outbreak in China. Retrieved from https://www.cfr.org/blog/biggest-animal-disease-outbreak-china.

Jeyakumar, S., Sunder, J., Kundu, A., Balakrishnan, P., Kundu, M. S., \& Srivastava, R. C. (2014).

Nicobari pig: an indigenous pig germplasm of the Nicobar group of Islands, India. Animal Genetic Resources/Resources génétiques animales/Recursos genéticos animales, 55, 77-86.

Jia, N., Ou, Y., Pejsak, Z., Zhang, Y., \& Zhang, J. (2017). Roles of African swine fever virus structural proteins in viral infection. Journal of veterinary research , 61 (2), 135-143.

Kalra, S. L., \& Rao, K. N. A. (1951). Observations on the epidemiology of relapsing fever in Kashmir. Indian Journal of Medical Research , 39 (3), 319-211. 
Kimberling, C. V., \& Teegarden, R. M. (1979). African swine fever. Service in action; no. 8.015 .

Kumar, A., Staal, S. J., Elumalai, K., \& Singh, D. K. (2007). Livestock sector in north-eastern region of India: An appraisal of performance. Agricultural Economics Research Review, 20(347-2016-16637), 255-272.

Kumar, K., Balakrishnan, N., \& Sharma, A. K. (2014). Studies on the vertical distribution of ticks of domestic animals and their public health importance in Nilgiri Hills and adjoining areas of Tamil Nadu State (India). International Journal of Zoology, 2014.

Kumar, R., Prakash, N., \& Naskar, S. (2004). Livestock management practices by the small holders of north eastern region. The Indian Journal of Animal Sciences, 74 (8).

Kumaresan, A., Bujarbaruah, K. M., Pathak, K. A., Das, A., \& Bardoloi, R. K. (2009). Integrated resource-driven pig production systems in a mountainous area of Northeast India: production practices and pig performance. Tropical animal health and production, 41(7), 1187. Labonté, R., Mohindra, K. S., \& Lencucha, R. (2011). Framing international trade and chronic disease. Globalization and Health, 7(1), 21.

Linden, J. (2020). India reports first cases of African swine fever. Retrieved from

https://www.feedstrategy.com/africaswine-fever/india-reports-first-cases-of-african-swine-fever/.

Livestock Census. (2019). 20 ${ }^{\text {th }}$ Livestock Census. All India Report. Retrieved from

http://dahd.nic.in/division/provisional-key-results-20th-livestock-census

Mackie, F. P. (1907). The part played by Pediculus corporis in the transmission of relapsing

fever. British medical journal, 2 (2450), 1706.

Manzano-Román, R., Díaz-Martín, V., de la Fuente, J., \& Pérez-Sánchez, R. (2012). Soft ticks as

pathogen vectors: distribution, surveillance and control. Parasitology , 7 , 125-162.

Mebus, C., Arias, M., Pineda, J. M., Tapiador, J., House, C., \& Sanchez-Vizcaino, J. M. (1997).

Survival of several porcine viruses in different Spanish dry-cured meat products. Food Chemistry, 59(4), $555-559$.

Meijaard, E., Narayan, G., \& Deka, P. (2019). Porcula salvania. The IUCN Red List of Threatened Species 2019: e.T21172A44139115.

Mohakud, S. S., Hazarika, R. A., Sonowal, S., Bora, D. P., Talukdar, A., Tamuly, S., \& Lindahl, J. F. (2020). The extent and structure of pig rearing system in urban and peri-urban areas of Guwahati. Infection Ecology \& Epidemiology, 10(1), 1711576.

Monteagudo, P. L., Lacasta, A., López, E., Bosch, L., Collado, J., Pina-Pedrero, S., .. \& Bustos, M. J. (2017). BA71 $\triangle$ CD2: a new recombinant live attenuated African swine fever virus with cross-protective capabilities. Journal of virology, $91(21)$.

Montgomery, R. E. (1921). On a form of swine fever occurring in British East Africa (Kenya

Colony). Journal of comparative pathology and therapeutics , 34 , 159-191.

Mukherjee, P., Karam, A., Barkalita, L., Borah, P., Chakraborty, A. K., Das, S., .. \& Laha, R. G. (2018).

Porcine circovirus 2 in the North Eastern region of India: Disease prevalence and genetic variation among the isolates from areas of intensive pig rearing. Acta tropica, 182, 166-172.

Mulumba-Mfumu, L. K., Saegerman, C., Dixon, L. K., Madimba, K. C., Kazadi, E., Mukalakata, N. T., 
.. \& \& Thiry, E. (2019). African swine fever: update on Eastern, Central and Southern Africa. Transboundary and emerging diseases, 66(4), 1462-1480.

Muthuramalingam, T., Gnanaraj, P., Sivakumar, T., Murallidharan, R., \& Murugan, M. (2011).

Influence of Heat-treated swill feed on the performance of large white yorkshire pigs. $J$ Veterinary $\&$ Animal Sciences, 7, 312-314.

Naish, D. (2015). Fabulous Crested Indian Wild Pigs. Retrived from

https://blogs.scientificamerican.com/tetrapod-zoology/fabulous-crested-indian-wild-

pigs/\#: :text=cristatus\%20of\%20India\%2C\%20Sri\%20Lanka,it\%20a\%20sometimes\%20prominent\%20beard.

Netherton, C. L., Connell, S., Benfield, C. T., \& Dixon, L. K. (2019). The genetics of life and death:

virus-host interactions underpinning resistance to African swine fever, a viral hemorrhagic disease. Frontiers in genetics, 10, 402 .

NRC Pig. (2011). National Research Station in Pig. Vision 2030. Retrieved from

http://www.nrcp.in/pdf/NRCP_vision_2030_protected.pdf

Nunn, C. L., Jordán, F., McCabe, C. M., Verdolin, J. L., \& Fewell, J. H. (2015). Infectious disease and

group size: more than just a numbers game. Philosophical Transactions of the Royal Society B: Biological Sciences, 370(1669), 20140111.

O’Donnell, V., Holinka, L. G., Krug, P. W., Gladue, D. P., Carlson, J., Sanford, B., .. \& Reese, B.

(2015). African swine fever virus Georgia 2007 with a deletion of virulence-associated gene 9GL (B119L), when administered at low doses, leads to virus attenuation in swine and induces an effective protection against homologous challenge. Journal of virology, 89(16), 8556-8566.

O’Donnell, V., Holinka, L. G., Krug, P. W., Gladue, D. P., Carlson, J., Sanford, B., .. \& Reese, B.

(2015). Deletion of African Swine Fever Virus Georgia 2007 virulence-associated gene 9GL (B119L) leads to virus attenuation in swine at low doses while inducing an effective protection against homologous challenge. Journal of Virology, JVI-00969.

O’Donnell, V., Risatti, G. R., Holinka, L. G., Krug, P. W., Carlson, J., Velazquez-Salinas, L., .. \& \&

Borca, M. V. (2017). Simultaneous deletion of the 9GL and UK genes from the African swine fever virus Georgia 2007 isolate offers increased safety and protection against homologous challenge. Journal of virology, $91(1)$.

OIE. (2019a). African Swine Fever. Retrieved from

https://www.oie.int/fileadmin/Home/eng/Animal_Health_in_the_World/docs/pdf/Disease_cards/AFRICAN_SWINE_FEVER.pdf

OIE. (2019b). Chapter 7.6. Killing of Animals for Disease Control Purposes. Terrestrial Animal Health Code. Retrived from https://www.oie.int/fileadmin/Home/eng/Health_standards/tahc/current/chapitre_aw_killing.pdf

OIE. (2020a). OIE-Listed diseases, infections and infestations in force in 2020. Retrieved from https://www.oie.int/en/animal-health-in-the-world/oie-listed-diseases-2020/

OIE. (2020b). African swine fever, India. Retrieved from

https://www.oie.int/wahis_2/public/wahid.php/Reviewreport/Review?page_re-

fer $=$ MapFullEventReport\&reportid $=34283$

Patra, M. K., Begum, S., \& Deka, B. C. (2014). Problems and prospects of traditional pig farming for 
tribal livelihood in Nagaland. Indian Research Journal of Extension Education, 14 (4), 6-11.

Penrith, M. L., \& Vosloo, W. (2009). Review of African swine fever: transmission, spread and

control. Journal of the South African Veterinary Association , 80 (2), 58-62.

Penrith, M.L. (2009). African swine fever. Onderstepoort Journal of Veterinary Research , 76 (1), 91-

5.

Plowright, W., \& Parker, J. (1967). The stability of African swine fever virus with particular reference to heat and pH inactivation. Archiv für die gesamte Virusforschung , 21 (3-4), 383-402.

Plowright, W., Perry, C. T., \& Peirce, M. A. (1970). Transovarial infection with African swine fever virus in the argasid tick, Ornithodoros moubata porcinus, Walton. Research in veterinary science, 11(6), $582-584$.

Plowright, W., Thomson, G. R. \& Neser, J. A. (1994) African swine fever. In Infectious diseases of livestock, with special reference to southern Africa, vol 1 (eds J. A. W. Coetzer, G. R. Thomson \& R. C. Tutsin), pp. 567-599, 1st edn. Cape Town, South Africa: Oxford University Press.

Probst, C., Globig, A., Knoll, B., Conraths, F. J., \& Depner, K. (2017). Behaviour of free ranging wild boar towards their dead fellows: potential implications for the transmission of African swine fever. Royal Society open science, 4(5), 170054.

Rajkhowa, T. K., Jagan Mohanarao, G., Gogoi, A., Hauhnar, L., \& Isaac, L. (2015). Porcine reproductive and respiratory syndrome virus (PRRSV) from the first outbreak of India shows close relationship with the highly pathogenic variant of China. Veterinary Quarterly, 35(4), 186-193. Ramesh, V., Kumar, V., Sivakumar, K., Singh, D., \& Thiruvenkadan, A. K. (2012). Effect of swill feeding on the reproductive performance of large white yorkshire pigs. Indian Journal of Field Veterinarians (The), 8(2), 42-45.

Ravaomanana, J., Jori, F., Vial, L., Pérez-Sanchez, R., Blanco, E., Michaud, V., \& Roger, F. (2011).

Assessment of interactions between African swine fever virus, bushpigs (Potamochoerus larvatus), Ornithodoros ticks and domestic pigs in north-western Madagascar. Transboundary and emerging diseases, 58(3), 247-254.

Reis, A. L., Goatley, L. C., Jabbar, T., Sanchez-Cordon, P. J., Netherton, C. L., Chapman, D. A., \&

Dixon, L. K. (2017). Deletion of the African swine fever virus gene DP148R does not reduce virus replication in culture but reduces virus virulence in pigs and induces high levels of protection against challenge. Journal of virology, $91(24)$.

Rock, D. L. (2017). Challenges for African swine fever vaccine development “... perhaps the end of the beginning.". Veterinary microbiology, 206 , 52-58.

Sahu, S., Sarangi, A., Gulati, H. K., \& Verma, A. (2018). Pig farming in Haryana: a review. International Journal of Science, Environment and Technology, 7 , 624-632.

Sanchez-Vizcaino, J.M. (2010). Early detection and contingency plans for African swine fever.

Compendium of technical items presented to the OIE World Assembly of Delegates and to OIE Regional Commissions.129-68. 
Schulz, K., Staubach, C., \& Blome, S. (2017). African and classical swine fever: similarities, differences and epidemiological consequences. Veterinary research , 48 (1), 1-13.

Sharma, N., Singh, V., Shyma, K. P., \& Parsani, H. R. (2017). Comparative efficacy of commercial preparation of deltamethrin and cypermethrin against Ornithodoros spp. of North Gujarat. Journal of Parasitic Diseases, 41(4), 1139-1142.

Sharma, N., Singh, V., Shyma, K. P., \& Parsani, H. R. (2017). Comparative efficacy of commercial preparation of deltamethrin and cypermethrin against Ornithodoros spp. of North Gujarat. Journal of Parasitic Diseases, 41(4), 1139-1142.

Shyam, J., Tripathi, H. E. M. A., \& Balaraju, B. L. (2016). Backyard Pig Rearing Practices Among Tribals of Assam. Advances in Life Sciences , 5 (18), 2278-3849.

Shyma, K. P., Singh, V., \& Gupta, J. P. (2019). Susceptibility Level of Ornithodoros spp.(Acari: Argasidae) to Some Commercial Synthetic Pyrethroids in North Gujarat. Int. J. Livest. Res, 9(3), 62-67. Singh, N. M., Singh, S. B., \& Singh, S. K. (2019). Small Scale Pig Farming in Manipur, India: A Study on Socio-Personal and Socio-Economical Status of the Small Scale Tribal Farming Community. International Journal of Current Microbiology and Applied Sciences, 8(8), 1158-1168.

Talukdar, P., Talukdar, D., Sarma, K., \& Saikia, K. (2019). Prospects and Potentiality of Improving Pig Farming in North Eastern Hill Region of India: An Overview. International Journal of Livestock Research, 9(1), 1-14.

USDA FAS. (2016). Global Agricultural Information Network. Retrieved from

https://www.fas.usda.gov/data/india-pork-2016

Veena, S., Seema, V., \& Babu, R. (2013). Borreliosis: Recurrent fever due to spirochetes. Annals of

Tropical Medicine and Public Health , 6 (4), 482.

Wilkinson, P. J. (1984). The persistence of African swine fever in Africa and the

Mediterranean. Preventive Veterinary Medicine, 2 (1-4), 71-82.

FIGURE LEGENDS

FIGURE 1. Risk of African Swine Fever transmission associated with different pig farming practice in India

FIGURE 2. Epidemiological cycle of African Swine Fever consisting of (a) sylvatic, (ii) tick-pig (iii) domestic and (iv) wild-boar habitat cycle

FIGURE 3. Risk identification and assessment of African Swine Fever as per the socioeconomic and geographic conditions of India and critical action plans to prevent future outbreaks 


\section{Pig farming practice in India}

\begin{tabular}{|c|c|c|}
\hline \multicolumn{2}{|r|}{$\begin{array}{l}\text { Total pig population (2019) } \\
9.06 \text { Million (M) }\end{array}$} & \multirow{2}{*}{$\begin{array}{l}\text { otic/Cross-bred } \\
1.90 \mathrm{M}\end{array}$} \\
\hline \multicolumn{2}{|c|}{$\begin{array}{c}\text { Indigenous/Non-descript } \\
7.16 \mathrm{M}\end{array}$} & \\
\hline Backyard & Small-scale & Commercial \\
\hline 2-3 pigs/family & 10-15 pigs/family & 50-500 pigs/enterprise \\
\hline \multicolumn{3}{|c|}{ Risk of ASF transmission associated with each farming practice } \\
\hline $\begin{array}{l}\text { Free ranging/Tethering pigs } \\
\text { - Untreated swill feed } \\
\text { - Contaminated feed/water } \\
\text { Contaminated fomites } \\
\text { No quarantine measures } \\
\text { Unorganized abattoirs } \\
\text { Home slaughter } \\
\text { - Local open pork markets } \\
\text { Disposal of carcass in jungles/rivers }\end{array}$ & $\begin{array}{l}\text { Confined pigs } \\
\text { - Pig farms located nearby human dwellings } \\
\text { - Improper quarantine of incoming piglets } \\
\text { - Transport of sick piglets } \\
\text { - Unorganized abattoirs } \\
\text { - Lack of animal health managemental } \\
\text { practices } \\
\text { - Lack of biosecurity in farm and carcass } \\
\text { disposal }\end{array}$ & $\begin{array}{l}\text { Confined pigs } \\
\text { - Lack of biosecurity at farm level } \\
\text { - Pig buyers/visitors/workers with no } \\
\text { protective clothing or footwears } \\
\text { - Transport and slaughter of sick piglets } \\
\text { - Transport of contaminated pork and } \\
\text { pork products } \\
\text { - Improper management practices } \\
\text { - Lack of biosecurity in carcass disposal }\end{array}$ \\
\hline
\end{tabular}

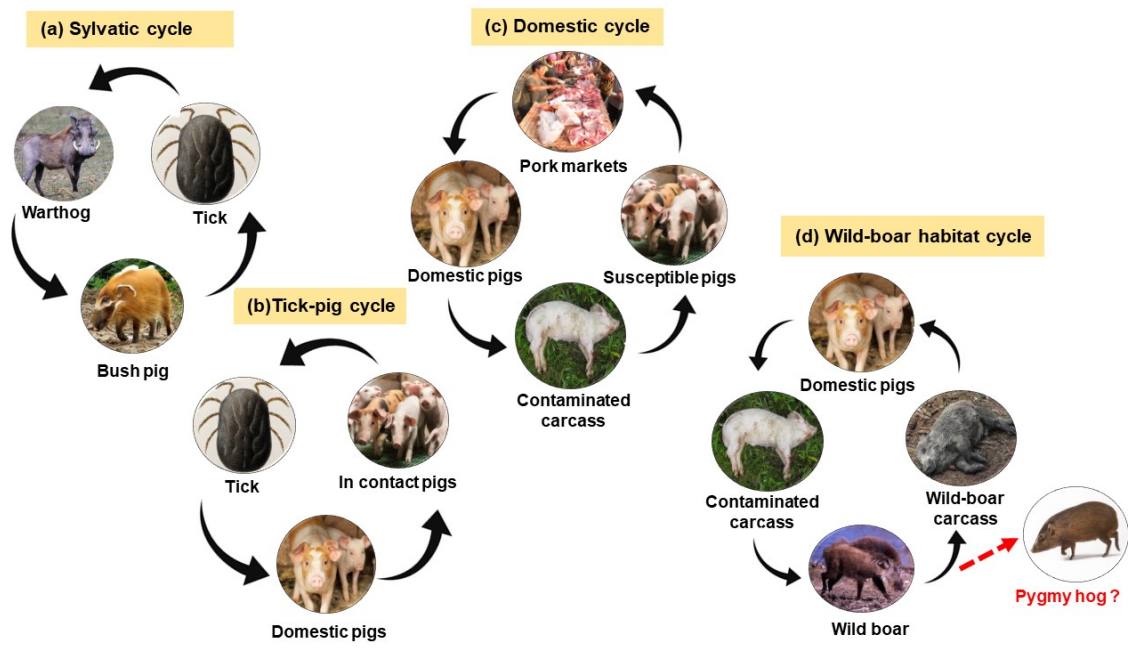

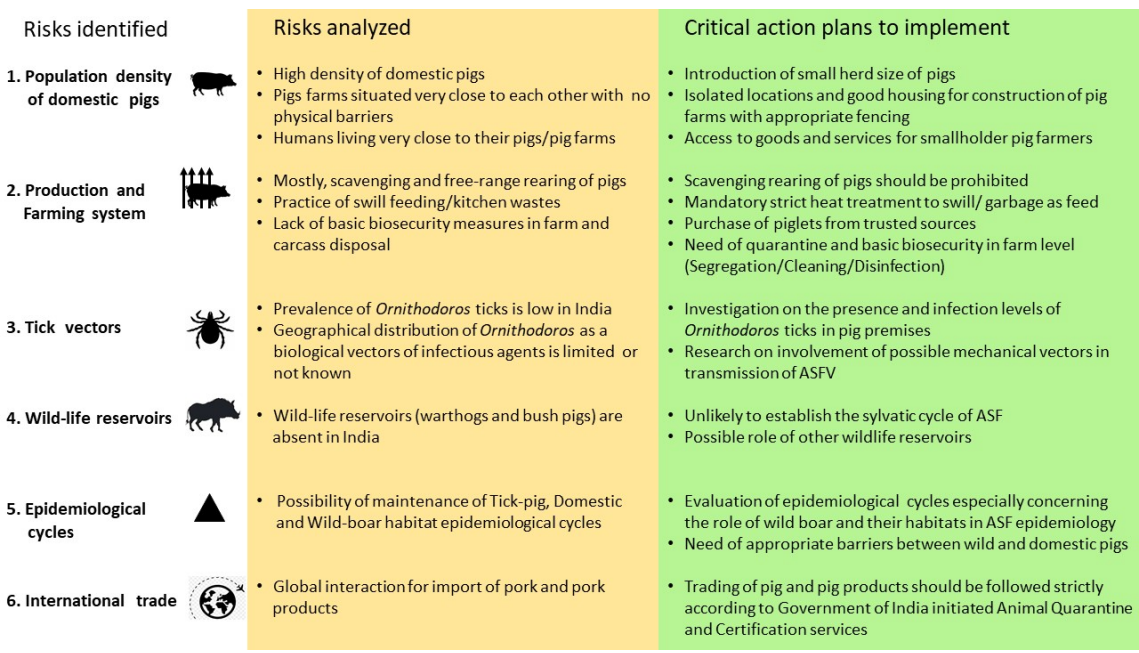

